\title{
Characteristics of asthma in the elderly
}

\author{
P. Weiner, R. Magadle, J. Waizman, M. Weiner, M. Rabner, D. Zamir
}

Characteristics of asthma in the elderly. P. Weiner, R. Magadle, J. Waizman, M. Weiner, M. Rabner, D. Zamir. (OERS Journals Ltd 1998.

ABSTRACT: Asthma occurs more frequently in the elderly than is usually appreciated and may, therefore, be underdiagnosed and undertreated. This study evaluated the relationship between asthma symptoms and the degree of airflow obstruction in elderly and young asthmatics.

Fifteen young asthmatics ( $<65$ yrs) (group A), 15 aged $>65$ yrs with onset of symptoms before 65 yrs (group B), and 15 aged $>65$ yrs with onset of symptoms after 65 yrs (group C), were studied. Patients used daily diary cards, during 2 weeks, to record inhaled $\beta_{2}$-agonist consumption and severity of asthma symptoms.

Long-standing asthma was associated with a significantly lower forced expiratory volume in one second as compared with recent onset asthma. The asthma-symptom score was highest in group A, lower in group B and significantly lower in group $\mathbf{C}$. When symptoms were related to the degree of obstruction (asthma index), it was higher in the young asthmatics than in both groups of elderly patients.

In conclusion, elderly patients with long-standing asthma had more severe airway obstruction than patients with recently acquired disease. Older patients particularly those with long-standing disease complained less about asthma symptoms. Within the various groups of patients, subjective symptoms of asthma were negatively related to asthma duration.

Eur Respir J 1998; 12: 564-568.

Asthma is frequently underdiagnosed and undertreated in the elderly. This may be due to diagnosis misclassification or under-reporting of symptoms [1]. Only a few studies, with a small number of patients, have reported the characteristics of older patients with asthma [2-5]. The underdiagnosis may occur because of an age-related reduction in perception of shortness of breath [6]. The difficulties of diagnosis of asthma in the elderly were pointed out by LeE and STRETTON [2] in 1973, who described 15 patients with the onset of asthma after the age of $60 \mathrm{yrs}$. In a recent population-based study [7], 52 females and 46 males with onset of asthma after the age of 65 yrs were identified among 3,622 residents of Rochester (MN, USA). In addition, they found that long-standing asthma may lead to chronic persistent airflow obstruction.

Many elderly patients with asthma have been treated in the authors' clinic. Thus affording the opportunity to characterize asthma in the elderly and to compare younger patients with asthma to older patients, who either developed asthma at an advanced age ( $>65 \mathrm{yrs})$ or acquired the disease as younger adults $(<65 \mathrm{yrs})$.

\section{Methods}

Over a period of 3 yrs, 15 consecutive patients with asthma, who were younger than 65 yrs ("younger asthmatics", group A), 15 consecutive patients aged $>65$ yrs, in whom the onset of symptoms was before the age of $65 \mathrm{yrs}$ ("elderly asthmatics, long duration", group B) and 15 consecutive patients aged $>65$ yrs, with onset of symptoms after the age of 65 yrs ("elderly asthmatics, late onset", group C), were studied. The relatively long period of patient collection was due to difficulty in recruiting patients for the third group who met all of the inclusion criteria (especially nonsmoking patients). Each patient satisfied the American Thoracic Society definition of asthma, with symptoms of episodic wheezing, cough and shortness of breath responding to bronchodilators, and reversible airflow obstruction documented in at least one previous pulmonary function study [8]. All patients had been instructed to use inhaled salbutamol "as needed". All had been on chronic inhaled steroid treatment for at least 3 months, but the exact duration could not be defined since many patients either forgot, were referred from other clinics with no documentation, were new immigrants in Israel, or did not receive the drug continuously. Smoking patients, those with only a partial response to inhaled $\beta_{2}$-agonist $(<30 \%$ improvement of forced expiratory volume in one second (FEV1)), those who were on chronic oral steroids and patients with a history of cardiac disease were excluded from the study. No patient had a significant chest wall deformation that might affect lung function. Firm inclusion and exclusion criteria were used to avoid the possibility of recruiting patients with chronic obstructive pulmonary disease (COPD) instead of pure asthma to our study. Patients used daily diary cards for 2 weeks, during a stable period of their disease when there was no change in medication, to record inhaled $\beta_{2}$-agonist consumption (0: no inhalation; 1 : one of two inhalations $\cdot$ day $^{-1} ; 2$ : three or four inhalations.day ${ }^{-1}$; 3 : five or six inhalations. day $^{-1}$; 4 : $>$ six inhalations $\cdot$ day $^{-1}$ ) (the mean of the two-week study period 
was considered as the "inhalation score"), and severity of asthma symptoms as follows: 1) Night-time asthma, recorded each morning (0: no asthma; 1: slightly wheezy; 2: woke once because of asthma; 3: woke several times because of asthma; 4: awake most of night because of asthma). The mean of the two week study period was considered as the "night-time asthma score". 2) Daytime asthma, recorded each evening (0: no asthma; 1 : occasional wheezing or breathlessness; 2 : frequent wheezing or breathlessness; 3: wheezing or breathlessness for most of the day which interfered with normal activities; 4: breathlessness so bad that it prevented the patient attending work or school). The mean of the two week study period was considered as the "daytime asthma score". 3) Cough recorded each evening ( 0 : no cough; 1: occasional cough; 2 : frequent coughing but with no interference with normal activities; 3: frequent coughing which interfered with normal activities; 4: cough so bad that it prevented normal activities). The mean of the two week study period was considered as the "cough score".

The "asthma symptom score" was calculated as the sum of all of these mean parameters (inhaled $\beta_{2}$-agonist consumption, night-time asthma, daytime asthma, and cough) and this value is reported.

Table 1. - Characteristics and symptoms of the study subjects

\begin{tabular}{|c|c|c|c|c|c|c|}
\hline $\begin{array}{l}\text { Patient } \\
\text { No. }\end{array}$ & Sex & $\begin{array}{l}\text { Age } \\
\text { yrs }\end{array}$ & $\begin{array}{c}\text { Asthma duration } \\
\text { yrs }\end{array}$ & $\begin{array}{l}\text { FEV1 } \\
\% \text { pred }\end{array}$ & $\begin{array}{l}\text { Symptom } \\
\text { score }\end{array}$ & $\begin{array}{c}\text { Symptom } \\
\text { index }\end{array}$ \\
\hline \multicolumn{7}{|l|}{$\overline{\text { Group A }}$} \\
\hline 1 & $\mathrm{~F}$ & 29 & 28 & 86 & 4 & 344 \\
\hline 2 & M & 50 & 40 & 78 & 3 & 234 \\
\hline 3 & M & 28 & 12 & 50 & 10 & 500 \\
\hline 4 & M & 17 & 2 & 28 & 13 & 364 \\
\hline 5 & $\mathrm{~F}$ & 34 & 9 & 63 & 9 & 567 \\
\hline 6 & $\mathrm{~F}$ & 33 & 30 & 76 & 4 & 304 \\
\hline 7 & M & 50 & 21 & 48 & 8 & 384 \\
\hline 8 & $\mathrm{~F}$ & 45 & 11 & 74 & 9 & 666 \\
\hline 9 & M & 25 & 7 & 70 & 8 & 560 \\
\hline 10 & M & 34 & 33 & 66 & 6 & 396 \\
\hline 11 & $\mathrm{~F}$ & 26 & 5 & 56 & 9 & 504 \\
\hline 12 & $\mathrm{~F}$ & 45 & 6 & 34 & 13 & 442 \\
\hline 13 & $\mathrm{~F}$ & 27 & 24 & 87 & 4 & 348 \\
\hline 14 & $\mathrm{~F}$ & 48 & 25 & 79 & 4 & 316 \\
\hline 15 & $\mathrm{~F}$ & 37 & 32 & 68 & 5 & 340 \\
\hline \multirow{2}{*}{\multicolumn{7}{|c|}{ Group B }} \\
\hline & & & & & & \\
\hline 1 & $\mathrm{~F}$ & 69 & 22 & 49 & 7 & 343 \\
\hline 2 & $\mathrm{~F}$ & 82 & 27 & 38 & 6 & 228 \\
\hline 3 & M & 91 & 50 & 65 & 4 & 260 \\
\hline 4 & $\mathrm{~F}$ & 77 & 27 & 55 & 6 & 330 \\
\hline 5 & M & 84 & 35 & 34 & 9 & 306 \\
\hline 6 & $\mathrm{~F}$ & 73 & 16 & 39 & 10 & 390 \\
\hline 7 & $\mathrm{~F}$ & 81 & 30 & 60 & 6 & 360 \\
\hline 8 & M & 70 & 60 & 78 & 2 & 156 \\
\hline 9 & $\mathrm{M}$ & 76 & 27 & 56 & 8 & 448 \\
\hline 10 & M & 68 & 23 & 26 & 11 & 286 \\
\hline 11 & $\mathrm{~F}$ & 73 & 29 & 39 & 6 & 234 \\
\hline 12 & $\mathrm{~F}$ & 89 & 49 & 67 & 5 & 335 \\
\hline 13 & $\mathrm{~F}$ & 69 & 33 & 59 & 7 & 413 \\
\hline 14 & $\mathrm{M}$ & 74 & 27 & 46 & 6 & 276 \\
\hline 15 & $\mathrm{~F}$ & 9 & 40 & 55 & 6 & 330 \\
\hline \multirow{2}{*}{\multicolumn{7}{|c|}{ Group C }} \\
\hline & & & & & & \\
\hline 1 & $\mathrm{~F}$ & 72 & 5 & 82 & 4 & 328 \\
\hline 2 & $\mathrm{~F}$ & 80 & 8 & 46 & 9 & 414 \\
\hline 3 & M & 83 & 13 & 78 & 2 & 156 \\
\hline 4 & $\mathrm{~F}$ & 73 & 6 & 55 & 5 & 275 \\
\hline 5 & M & 70 & 3 & 62 & 8 & 496 \\
\hline 6 & M & 81 & 10 & 79 & 3 & 237 \\
\hline 7 & $\mathrm{~F}$ & 68 & 2 & 44 & 11 & 484 \\
\hline 8 & $\mathrm{~F}$ & 76 & 3 & 56 & 7 & 392 \\
\hline 9 & $\mathrm{~F}$ & 80 & 5 & 38 & 6 & 228 \\
\hline 10 & $\mathrm{~F}$ & 68 & 1 & 65 & 7 & 455 \\
\hline 11 & $\mathrm{M}$ & 84 & 6 & 47 & 9 & 423 \\
\hline 12 & $\mathrm{~F}$ & 77 & 10 & 78 & 3 & 234 \\
\hline 13 & $\mathrm{~F}$ & 79 & 8 & 80 & 2 & 160 \\
\hline 14 & $\mathrm{M}$ & 92 & 5 & 54 & 6 & 324 \\
\hline 15 & $\mathrm{~F}$ & 68 & 2 & 63 & 5 & 315 \\
\hline Mean \pm SEM & & $75 \pm 1.5$ & $6 \pm 1$ & $61.8 \pm 3.8$ & $5.3 \pm 0.7$ & $328 \pm 29$ \\
\hline
\end{tabular}

Group A: younger asthmatics; Group B: elderly asthmatics (early onset); Group C: elderly asthmatics (late onset); FEV1: forced expiratory volume in one second; F: females; M: male. 
In an attempt to correlate asthma symptoms to the degree of airflow obstruction, the "asthma index" $(\mathrm{FEV} 1 \times$ "asthma symptom score") is also reported.

The forced vital capacity (FVC) and the FEV1 were measured three times on a computerized spirometer (Compact, Vitalograph, Buckingham, UK) and the best effort is reported. Measurements were taken at 08:00 h on the first day of the study and at the same time on the morning following the two week study period. The mean of the two best trials (the best at the beginning and the best at the end of the 2 weeks) is reported as the mean+SEM value for each patient. Pulmonary function tests took place after discontinuing bronchodilator therapy for at least $12 \mathrm{~h}$ and inhaled corticosteroids for at least $24 \mathrm{~h}$.

\section{Statistics}

Pearson correlation coefficients and linear regression analysis allowed examination of relationships among the different variables. Significance was accepted if $p<0.05$. Comparisons of lung function between the groups were carried out using the two-way repeated measures analysis of variance (ANOVA).

\section{Results}

The characteristics of the 15 patients with asthma, younger than 65 yrs ("younger asthmatics", group A), the 15 patients aged $>65$ yrs, in whom the onset of symptoms was before the age of 65 ("elderly asthmatics, long duration", group B) and the 15 patients aged $>65$ yrs, with onset of symptoms after the age of 65 ("elderly asthmatics late onset", group C) are presented in table 1.

The mean age of the elderly asthmatics in group B did not differ significantly from that of those in group C. However, there was a significant difference in the mean FEV1 between the two groups $(61.8 \pm 3.8$ versus $51.1 \pm 3.6 \%$ of predicted normal values, $\mathrm{p}<0.005)$.

The mean asthma duration in group A was $19 \pm 3.2$ yrs versus $33.0 \pm 3.1 \mathrm{yrs}$ in group $\mathrm{B}$, and only $5.8 \pm 0.9 \mathrm{yrs}$ in group C. However, as mentioned before, long-standing asthma (group B) was associated with a significantly lower FEV1 compared with recent-onset asthma (group C) and younger asthmatic patients with significantly shorter duration of symptoms (group A).

As can be seen in table 1, the mean asthma symptom score was highest in the younger asthmatics $(7.3 \pm 0.8)$, lower (although not statistically significant) in the elderly asthmatics long-duration group $(6.6 \pm 0.6)$ and significantly lower in the elderly asthmatics, late onset group $(5.3 \pm 0.7, \mathrm{p}<0.05)$. This was true for all parameters that constitute the asthma symptom score.

When the asthma index was compared among the groups (table 1), it was significantly higher in the younger asthmatics $(418 \pm 30.6)$, than in both groups of elderly patients $(313 \pm 20$ in group B and $328 \pm 29$ in group $C, p<0.01)$.

Within the three groups the asthma symptom score was closely related to percentage FEV 1 levels $\left(r^{2}=0.791, r^{2}=\right.$ 0.633 and $\mathrm{r}^{2}=0.649$, respectively) (fig. 1). However, looking at the different regression lines it can be seen that for each degree of obstruction (assessed by the FEV1 value)

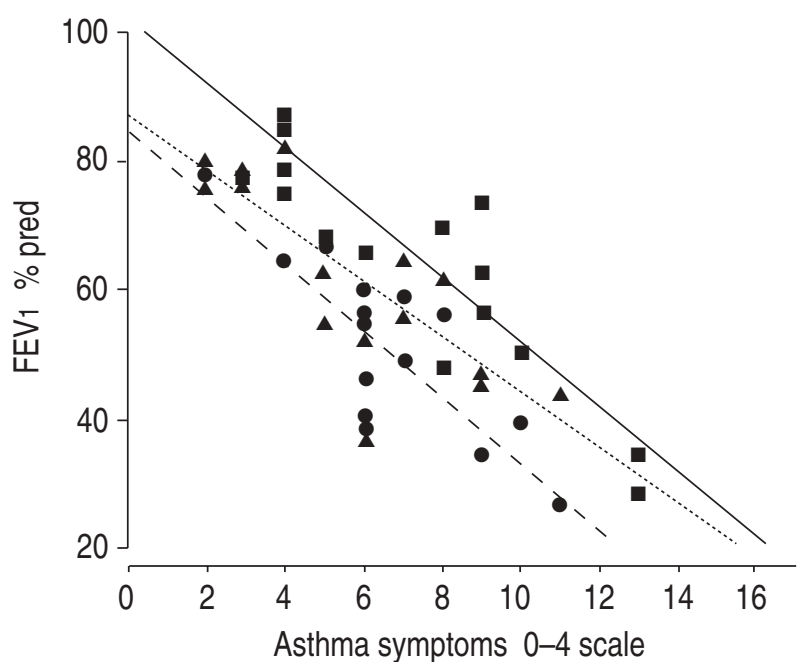

Fig. 1. - Relationship between the degree of airway narrowing (as expressed by the forced expiratory volume in one second (FEV1)) and asthma symptoms (night-time asthma, daytime asthma, cough and $\beta_{2^{-}}$ agonist consumption) in the three groups of patients. $\mathbf{m}$ : younger asthmatics ( $\left.-\mathrm{r}^{2}=0.791\right)$; $\bullet$ : elderly asthmatics (early onset) $(----$ : $\left.\mathrm{r}^{2}=0.653\right) ; \boldsymbol{\Delta}$ : elderly asthmatics (late onset) $\left(-------: \mathrm{r}^{2}=0.649\right)$.

there is a higher degree of subjective complaints (assessed by the asthma symptom score) in the group of younger asthmatics (group A), lower in the elderly subjects with late onset of asthma (group C) and the lowest in the elderly subjects with a long duration of asthma (group B).

In an attempt to investigate the relationship between asthma symptoms, the degree of obstruction and duration of asthma, the correlation between the asthma index and asthma duration was studied (fig. 2). Overall, there was no strong correlation between asthma duration and asthma index, although a negative correlation $\left(r^{2}=0.144\right)$ was found that reached statistical significance $(\mathrm{p}<0.05)$. For each group, there was a close negative correlation between the two parameters $\left(\mathrm{r}^{2}=0.512, \mathrm{p}<0.001 ; \mathrm{r}^{2}=0.225, \mathrm{p}<0.005\right.$; $\mathrm{r}^{2}=0.518, \mathrm{p}<0.001$, respectively) (fig. 3 ).

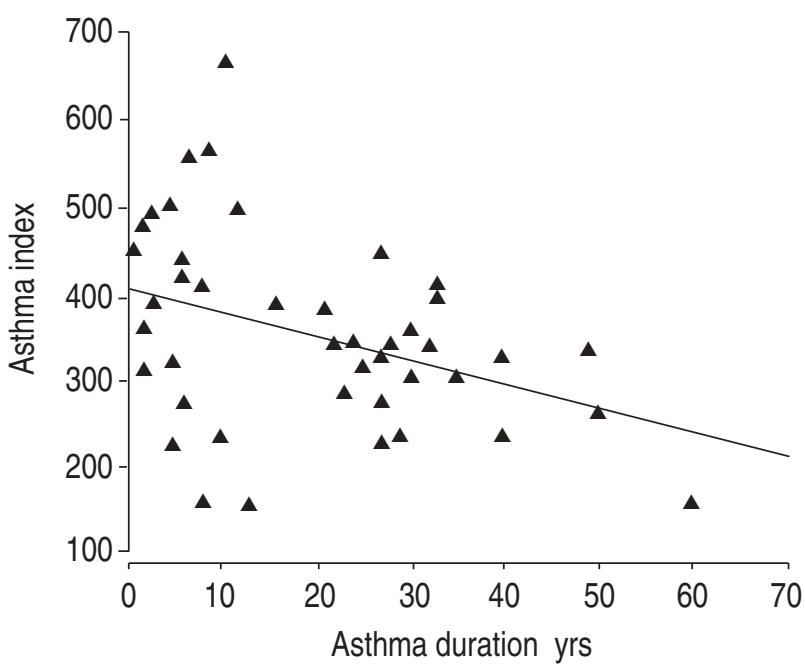

Fig. 2. - Relationship between asthma index (asthma symptoms $\times$ forced expiratory volume in one second) and asthma duration in the whole group of asthmatics. 

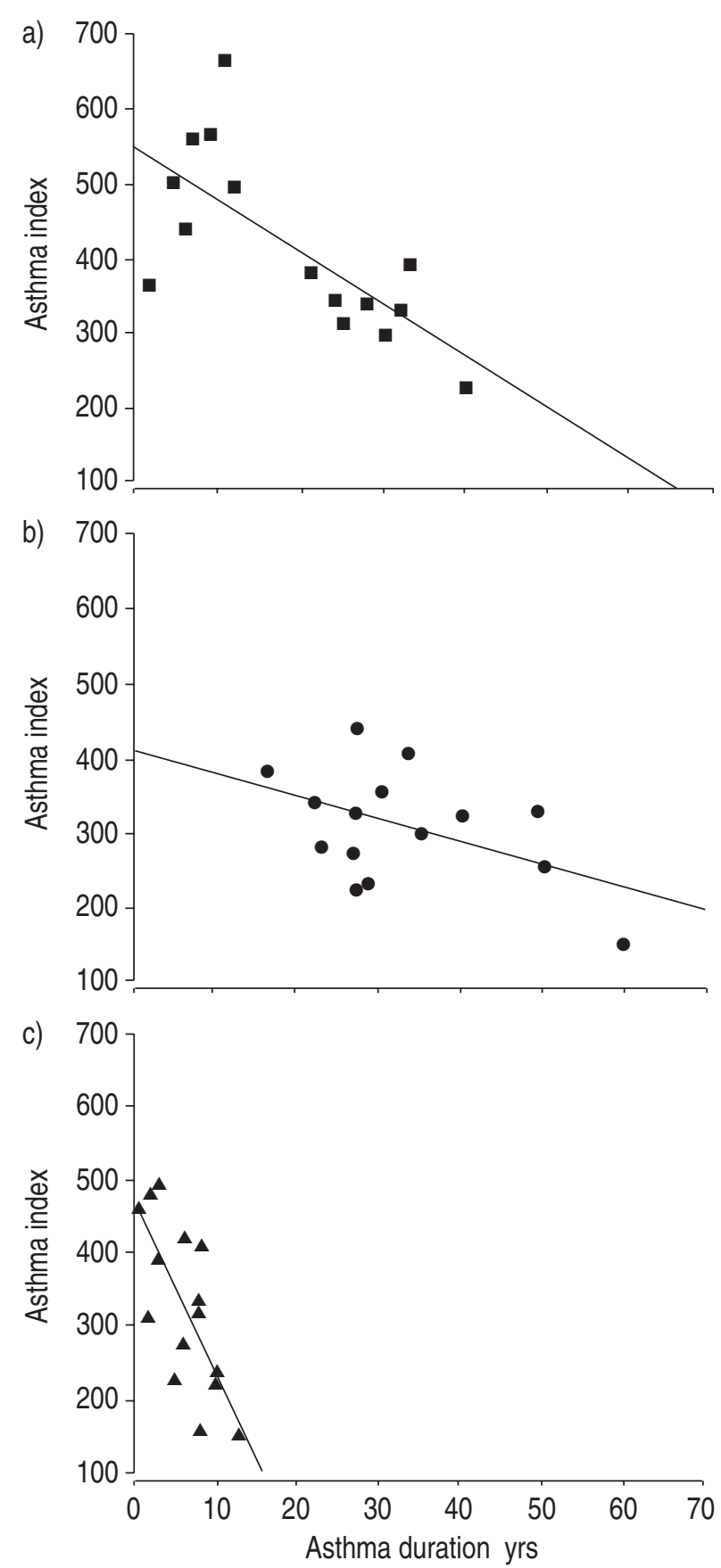

Fig. 3. - Relationship between asthma index (asthma symptoms $\times$ forced expiratory volume in one second) and asthma duration in a) younger asthmatics $\left(r^{2}=0.512\right)$, b) elderly asthmatics with a long duration of symptoms $\left(r^{2}=0.225\right)$, and c) elderly asthmatics with a late onset of symptoms $\left(\mathrm{r}^{2}=0.518\right)$.

\section{Discussion}

This study has shown that elderly patients with longstanding asthma have more severe airway obstruction than patients with recently acquired disease. It could be suggested that long-standing asthma may lead to a progressive loss of lung function. It has also been shown that older patients complain less about asthma symptoms and this is especially true in patients with long-standing disease. In addition, it was clearly shown that within the various groups of patients, subjective symptoms of asthma were related to asthma duration.

It was suggested previously that patients with longstanding asthma have more severely impaired pulmonary function [5,9]. A longitudinal study of the rate of decline of lung function in asthma [10] provides additional evidence that a progressive loss of lung function occurs in asthma. However, the longitudinal epidemiological study in Copenhagen [11] demonstrated that while patients with newly diagnosed asthma experienced a more rapid rate of decline of FEV 1 than the general population, patients with chronic asthma did not. In addition, inhaled corticosteroids have been shown to slow this decline, at least in patients with extremely high rates of decline to start with $[12,13]$. One can speculate, then, that if aggressive antiinflammatory therapy had been started earlier in the course of the disease some of this damage to the airways may have been prevented. However, the situation is much more complicated since many patients with deterioration in lung function despite aggressive treatment with corticosteroids have been described [14].

The mechanism of the progressive loss of lung function in asthma is not certain, but chronic airway inflammation may be an important factor in the process. The present study, which compared a group of elderly asthmatic patients with a mean duration of illness of 33 yrs with a group of similar age who had asthma for a mean of 5.8 yrs and a group of younger asthmatic patients with a mean duration of illness of $19 \mathrm{yrs}$, made clear that those with longstanding disease had more severely impaired pulmonary function. The duration of steroid treatment could not be established in the majority of our patients.

Connolly et al. [6] showed that there is a difference in the subjective reporting of dyspnoea, in response to acute bronchoconstriction, between elderly and young asthmatics. They related it to a decreased awareness of bronchoconstriction in the elderly. However, awareness was unrelated to duration of asthma in either young or elderly asthmatic patients. In part, the present results are in agreement with these findings. In both groups of elderly asthmatic subjects the asthma index was significantly lower than in the young asthmatics. This means that elderly asthmatics complain less than younger asthmatics with the same degree of bronchoconstriction. This difference may be due to the fact that older patients are less aware of airflow obstruction and therefore are complaining less than the younger patients. Elderly patients have impaired perception for externally applied respiratory loads [15] and this may contribute to their decreased awareness to added resistance due to bronchoconstriction. The possible causes of this in the elderly are numerous. Stretch receptors that may produce termination of deep inspiration may be involved. It is conceivable that impaired awareness of bronchoconstriction may result from a reduced number or activity of stretch receptors in old age [4]. The reduced sensitivity of chemoreceptors to hypoxia in the elderly [16] may also be relevant.

In contrast to the findings of ConNolly et al. [6], the present study found that the asthma index was inversely related to the duration of asthma in all subgroups of asthmatic patients. In the authors' opinion, the significance of this observation is that there is a process of adaptation to bronchoconstriction with time. When patients' complaints 
were related to the degree of bronchoconstriction it was clear that patients with long-standing disease complained less than patients with a recent-onset disease. Previous studies have shown that changes in lung volume, speed of bronchoconstriction, anxiety level and age are among the factors that can affect patients' complaints of bronchoconstriction $[17,18]$. The degree of dyspnoea reported by the patients was unrelated to the duration of asthma in some studies [6, 19]. However, in other studies [20, 21], it was suggested that as people grow older they may adapt to the presence of symptoms. It is known that prolonged periods of stimulation result in a consistent reduction in perceived magnitude, a process known as temporal adaptation [22, 23]. It is expected, therefore, that patients with prolonged and more consistent air flow obstruction will adapt to the sensation of dyspnoea and, for any degree of bronchoconstriction, will complain less than those with short-standing disease.

The process of adaptation and the possibility of impaired awareness of bronchoconstriction in the elderly may lead to under-reporting and under-recognition of the disease in this population [5, 24] and, therefore, it may also contribute to the increased rate of mortality from asthma [25-27] by leading to delayed self-referral during an acute asthmatic attack.

Mortality from asthma is higher in the elderly than in younger patients and continues to rise [16, 26, 27]. Acute attacks of asthma in older people may be rapidly fatal and have poorer prognosis than in the young [28]. Both chronicity [21] and impaired awareness of bronchoconstriction [29] may lead to the higher mortality in older asthmatics.

In conclusion, elderly patients with long-standing asthma were shown to have more severe airway obstruction than patients with recently acquired disease. They complained less about asthma symptoms and this was related to asthma duration. Asthma in the elderly merits more aggressive diagnostic studies and improved patient education, and treatment should be offered, especially because asthma is one of the few potentially reversible causes of morbidity and mortality in the elderly.

\section{References}

1. Dow L, Coggon D, Campbell MJ, Osmond C, Holgate ST. The interaction between immunoglobin $\mathrm{E}$ and smoking in airflow obstruction in the elderly. Am Rev Respir Dis 1992; 146: 402-407.

2. Lee HY, Stretton TB. Asthma in the elderly. BMJ 1973; 4: 93-95.

3. Burr ML, Charles TJ, Roy K. Asthma in the elderly: an epidemiological survey. BMJ 1979; 1: 1041-1044.

4. Petherman IS, Jones DA, Collins JV. Assessment and management of acute asthma in the elderly: a comparison with younger asthmatics. Postgrad Med J 1982; 58: 149151.

5. Braman SS, Kaemmerlen JT, Davis SM. Asthma in the elderly: a comparison between patient with recently acquired and long-standing disease. Am Rev Respir Dis 1991; 143: 336-340.

6. Connolly MJ, Crowley JJ, Charan NB, Nielson CP, Vestel RE. Reduced subjective awareness of bronchoconstriction provoked by methacholine in elderly asthmatic and normal subjects as measured on a simple awareness scale. Thorax 1992; 47: 410-413.

7. Bauer BA, Reed CE, Yunginger JW, Wollan PC, Silver- stein MD. Incidence and outcomes of asthma in the elderly: a population based study in Rochester, Minnesota. Chest 1997; 111: 303-310.

8. American Thoracic Society. Standards for the diagnosis and care of patients with chronic obstructive pulmonary disease (COPD) and asthma. Am Rev Respir Dis 1987; 136: 225-244.

9. Brown PJ, Greville HW, Finucane KE. Asthma and irreversible air-flow obstruction. Thorax 1984; 39: 131-136.

10. Peat JK, Woolcock AJ, Cullen K. Rate of decline of lung function in subjects with asthma. Eur J Respir Dis 1987; 70: 171-179.

11. Ulrik CS, Lange P. Decline of lung function in adults with bronchial asthma. Am J Respir Crit Care Med 1994; 150: 629-634.

12. Dompeling E, van Schayck CP, Molema J. Inhaled beclomethasone improves the course of asthma and COPD. Eur Respir J 1992; 5: 945-952.

13. Dompeling E, van Schayck CP, van Grunsven PM. Slowing the deterioration of asthma and COPD observed during bronchodilator therapy by adding inhaled corticosteroids - a 4-year prospective study. Ann Intern Med 1993; 118: 770-778.

14. Backman KS, Greenberger PA, Patterson R. Airways obstruction in patients with long-term asthma consistent with "irreversible asthma". Chest 1997; 112: 1234-1240.

15. Tack CM, Cherniack NS, Altose MD. Effect of aging on the perception of resistive respiratory loads. Am Rev Respir Dis 1982; 126: 463-467.

16. Kronenberg RS, Drage CW. Attenuation of the ventilatory and heart rate responses to hypoxia and hypercapnia with aging in normal man. J Clin Invest Pathol Res Pract 1973; 52: 1812-1819.

17. Orehek J, Beaupre A, Badier M, Nicoli MM, Delpierre S. Perception of airway tone by asthmatic patients. Bull Eur Physiopath Respir 1982; 18: 601-607.

18. Altose MD. Dyspnea In: Simmmons DH, ed. Current Pulmonology. Chicago, IL, Year Book Medical Publishers, 1986; pp. 199-226.

19. Boulet LP, Leblanc P, Turcotte H. Perception scoring of induced bronchoconstriction as an index of awareness of asthma symptoms. Chest 1994; 105: 1430-1433.

20. Sly RM. Increases in deaths from asthma. Ann Allergy 1984; 53: 20-25.

21. Unger L. Chronic bronchial asthma in the older age group. Med Clin North Am 1956; 40: 115-134.

22. Stevens JC, Stevens SS. Brightness function: effects of adaptation. J Opt Soc Am 1963; 53: 375-385.

23. Marks LP. Sensory Processes. The New Psychophysics. New York, Academic Press, 1974.

24. Burrows B, Barbee RA, Cline MG. Characteristics of asthma among elderly adults in a sample of the general population. Chest 1991; 100: 935-942.

25. MacDonald JB, Seaton A, Williams DA. Asthma deaths in Cardiff 1963-74: 90 deaths outside hospital. BMJ 1976; 1: 1493-1495.

26. Robin ED. Risk benefit analysis in chest medicine. Death from bronchial asthma. Chest 1988; 93: 614-618.

27. Buist SA. Is asthma mortality increasing? Chest 1988; 93: 449-450.

28. Burdon JGW, Juniper EF, Killian KJ, Hargreave FE, Campbell EJM. The perception of breathlessness in asthma. Am Rev Respir Dis 1982; 126: 825-828.

29. Gottfried SB, Altose MD, Kelsen SG, Cherniack NS. Perception of changes in airflow resistance in obstructive pulmonary disorder. Am Rev Respir Dis 1981; 124: 566 570. 